\title{
The Not-So-Common-Wealth of Australia: Evidence for a Cross-Cultural Desire for a More Equal Distribution of Wealth
}

\section{Citation}

Norton, Michael I., David T. Neal, Cassandra L. Govan, Dan Ariely, and Elise Holland. "The Not-So-Common-Wealth of Australia: Evidence for a Cross-Cultural Desire for a More Equal Distribution of Wealth." Analyses of Social Issues and Public Policy 14, no. 1 (December 2014): 339-351.

\section{Published Version}

http://onlinelibrary.wiley.com/wol1/doi/10.1111/asap.12058/full

\section{Permanent link}

http://nrs.harvard.edu/urn-3:HUL.InstRepos:28538432

\section{Terms of Use}

This article was downloaded from Harvard University's DASH repository, and is made available under the terms and conditions applicable to Open Access Policy Articles, as set forth at http:// nrs.harvard.edu/urn-3:HUL.InstRepos:dash.current.terms-of-use\#OAP

\section{Share Your Story}

The Harvard community has made this article openly available.

Please share how this access benefits you. Submit a story.

Accessibility 
The Not-So-Common-Wealth of Australia:

Evidence for a Cross-Cultural Desire for a More Equal Distribution of Wealth

Michael I. Norton, ${ }^{1} *$ David T. Neal, ${ }^{2}$ Cassandra L. Govan, ${ }^{2,3}$ Dan Ariely, ${ }^{4}$ and Elise Holland ${ }^{3}$

1. Harvard Business School

2. Empirica Research

3. The University of Melbourne

4. Duke University

Word Count: 3,405

Acknowledgements: This research was supported, in part, by a grant from the Australian Council of Trade Unions (ACTU).

*Correspondence concerning this article should be addressed to Michael I. Norton, Harvard Business School, Soldiers Field Road, Boston, MA 02163. Email: mnorton@hbs.edu 


\begin{abstract}
Recent evidence suggests that Americans underestimate wealth inequality in the United States and favor a more equal wealth distribution (Norton \& Ariely, 2011). Does this pattern reflect ideological dynamics unique to the United States, or is the phenomenon evident in other developed economies - such as Australia? We assessed Australians’ perceived and ideal wealth distributions and compared them to the actual wealth distribution. Although the United States and Australia differ in the degree of actual wealth inequality and in cultural narratives around economic mobility, the Australian data closely replicated the United States findings. Misperceptions of wealth inequality as well as preferences for more equal distributions may be common across developed economies. In addition, beliefs about wealth distribution only weakly predicted support for raising the minimum wage, suggesting that attitudes toward inequality may not translate into preferences for redistributive policies.
\end{abstract}




\section{The Not-So-Common-Wealth of Australia:}

\section{Evidence for a Cross-Cultural Desire for a More Equal Distribution of Wealth}

Just how much richer should the rich be than the poor and middle class? The recent rise of the worldwide “Occupy” movement - in countries ranging from Armenia to Denmark and Nigeria to Hong Kong - suggests a broad (and increasing) international concern with the size of the gap between the rich and poor. Recent research suggests that most Americans favor a far more equal wealth distribution than they perceive currently to exist (Norton \& Ariely, 2011). We present data from a national survey in Australia that allows us to explore similarities and differences in how Americans and Australians (each of whom had their own Occupy movement) perceive the current gap between rich and poor - as well as their ideal desires for the size of that gap. We also examine how these beliefs about inequality relate to preferences for policies that might affect that inequality, such as increases in the minimum wage.

Understanding wealth and income inequality is important from both an economic and a psychological perspective. Recent economic modeling suggests that sharp increases in wealth inequality can play a role in triggering large-scale financial crises. Noting a historical trend whereby major recessions over the last century have been preceded by increases in wealth inequality, Kumhof and Ranciere (2010) argue that rising wealth inequality fosters increased borrowing among the poor, which increases leverage and leaves societies vulnerable to the possibility of an economic crisis. Wealth inequality can also contribute to negative health and social outcomes, with research suggesting that highly unequal societies tend to be characterized by higher levels of obesity and drug abuse, higher levels of crime, lower levels of educational attainment and overall poorer psychological wellbeing (Napier \& Jost, 2008; Pickett \& Wilkinson, 2010; Wilkinson \& Pickett, 2009).

\section{Inequality in the United States and Australia}


In a nationally representative survey, Norton and Ariely (2011) found that US respondents estimated that the richest $20 \%$ of the population owns around $59 \%$ of total wealth, but believed that this richest quintile should ideally own just 32\%. In reality, however, the richest $20 \%$ owns closer to $84 \%$ of total wealth. Thus, despite strong cultural themes of economic mobility and rewarding individual enterprise, Americans favor greater wealth equality, even relative to their erroneously small estimates of the gap between rich and poor. Interestingly, Norton and Ariely (2011) found that this pattern transcended political identification; with liberals and conservatives alike underestimating the wealth gap and favoring a more equal distribution.

But are these dynamics driven by conditions that are unique to the US? Australia provides an interesting comparison point. According to government data, the richest $20 \%$ of Australians own $62 \%$ of the nation's wealth, while the poorest $20 \%$ hold less than $1 \%$ (ABS, 2011). This disparity has been on an upward trajectory over the past decade, with the top quintile increasing their share of the wealth by 3 percentage points since 2003-04 (ABS, 2006). However, wealth inequality has increased far more rapidly in the US than in Australia in recent decades. OECD data shows that, between the mid-1980s and the late 2000s, the gap between the richest $10 \%$ Americans and the poorest $10 \%$ grew by a factor of fifteen, whereas in Australia, the divide only increased by a factor of 1.5 (OECD, 2011). Thus, Norton and Ariely’s (2011) findings may, in part, reflect that public perceptions in the US have not kept pace with an exceptionally rapid rate of change, but have still exceeded a critical threshold where most people now favor greater equality. If so, the dynamics observed in the US may not generalize to other developed countries - like Australia - where the wealth gap is both somewhat smaller and has been growing at a slower pace.

The purpose of the current study was to extend upon Norton and Ariely’s (2011) work by exploring how Australians view wealth inequality, by seeking to answer four key questions. Are 
Australians accurate in their estimates of how wealth is distributed throughout the country, or, like Norton and Ariely's US sample, do they perceive the gap between the rich and poor to be smaller than is actually the case? Regardless of their perceptions, in what kind of society would they ideally like to live? Do people’s perceptions of the "ideal society" differ as a function of personal wealth and political ideology? Finally, in a novel direction not explored by Norton and Ariely (2011), how are perceptions of wealth inequality related to attitudes towards policies such as the minimum wage - that have the potential to alter wealth inequality?

\section{Method}

\section{Respondents}

We surveyed a nationally representative sample of 1,000 Australian adults, recruited through a research-only panel. Two respondents failed to provide demographic information, leading to a final sample of 998. The sample was matched to the demographics of the broader Australian population, with quotas specified for gender, age, employment status, state/territory, and metro/regional residence. All respondents completed the survey over a ten-day period in March 2011. A demographic profile of respondents can be found in Table 1.

\section{Materials and Procedure}

Perceptions of ideal and actual wealth distributions

The first task asked respondents to think of Australian households as divided into five quintiles, ranging from the richest to the poorest, with each group comprising $20 \%$ of the households. To gauge Australians' estimates of the actual distribution of wealth, we asked respondents to indicate what percent of Australians' total wealth was owned by each of the quintiles (with the total percent across all five groups summing to 100\%). We defined "wealth" as the sum of all major assets owned in a household (e.g., car, house, shares, superannuation, 
cash, etc.) minus any debts (e.g., mortgage, car loans, etc.) to ensure all respondents approached the task in the same manner.

After indicating how they thought Australians’ wealth was distributed, we asked respondents how they thought wealth ideally should be divided up among the quintiles; respondents again provided percentages for each of the quintiles. This methodology has been successfully used in prior research (Norton \& Ariely, 2011).

\section{Preferences for different societies}

In a second task, respondents were presented with three different pie charts, each representing the wealth distribution of three hypothetical countries, labeled Country A, Country B, and Country C (Figure r3a). In reality, these pie graphs represented (A) the actual wealth distribution in Australia, taken from ABS data from 2005-2006 (ABS, 2007), ${ }^{1}$ (B) the ideal distribution of wealth in the US as reported by a nationally representative sample (Norton and Ariely, 2011), and (C) a society in which there was a perfectly equal distribution of wealth. Each pie chart was split into five quintiles, with the size of each quintile reflecting the amount of wealth owned by that particular quintile. For each pie chart, respondents were asked to indicate how much they would like to live in that particular country, on a scale from 0 (definitely wouldn't like it) to 100 (definitely would like it). In making their decision, respondents were given a "Rawlsian veil of ignorance" by being told to imagine that if they joined any of the nations, they would be randomly placed in one of the quintiles, and so would have the same chance of ending up in any one group, from the richest to the poorest (Rawls, 1971). As in Norton and Ariely (2011), respondents were not trained on the pie chart task.

After indicating these ratings, respondents were presented with two more pie charts Country A and Country B (Figure 3b). These charts represented (A) Australia's actual wealth 
distribution, and (B) America's actual wealth distribution. Again, respondents were asked to indicate the extent to which they would like to live in each country.

Perceptions of, and attitudes towards, the minimum wage

Next, respondents were probed on their perceptions and attitudes towards the minimum wage. After being provided with a working definition of the minimum wage - "the lowest hourly or weekly wage that employers may legally pay to employees or workers” - respondents were asked to estimate the current adult national minimum wage in Australia per hour, on a scale ranging from AUD\$0 to AUD\$40. Second, we assessed attitudes towards increasing the minimum wage, using a 7-point scale (strongly oppose increasing to strongly support increasing). Finally, respondents were asked to rate their level of agreement with the following statement: “Government should adopt policies that promote wealth equality in Australia”, using a 7-point scale (disagree strongly to agree strongly).

Respondent demographics

Last, we obtained demographic information from respondents including political affiliation, their personal wealth, education, marital status, employment, gender, metro/regional residence, and age. In calculating personal wealth, we gave respondents a working definition that provided details on how to sum their assets and subtract their debts.

\section{Results}

Perceptions of ideal and actual wealth distributions within society

Figure 1 presents respondents’ perceived actual distribution and perceived ideal distributions across all five quintiles. ${ }^{2}$ It also shows the actual wealth distribution across quintiles in Australia at the time of testing (ABS, 2011). 
First, Australians vastly underestimated the degree of wealth inequality in society. This was especially evident in their estimates of the poorest and wealthiest quintiles, with Australians overestimating the wealth of the poorest quintile by a factor of more than seven, and underestimating the wealth of the wealthiest quintile by more than a fifth. These findings mirror those of Norton and Ariely (2011), suggesting that Australians also perceive less of gap between the rich and poor than is the case.

Second, these findings suggest that Australians prefer a society that is even more equal than they erroneously believe it to be, reporting a desire for the wealthiest quintile to own just over a third of the nation's wealth (34\%), and far less than what they own in reality (62\%). This pattern of findings closely matches Norton and Ariely’s (2011) US data.

We next explored whether respondents’ own personal wealth levels and their political affiliation affected their estimates and ideal distributions. First, we segmented respondents into one of the five quintiles based on their personal wealth. Similar to the findings reported by Norton and Ariely (2011), ideal distributions were also remarkably stable across all levels of wealth, indicating that Australians hold a strikingly similar view of what their country should look like.

Second, we explored how estimates and ideal distributions differed according to respondents' political orientation. For ease of interpretation, we collapsed political affiliation into three groups: (1) ALP/Greens/Democrats (i.e., left leaning voters); (2) Liberal Party/National Party (i.e., right leaning voters); and (3) Unaffiliated/Family First/Other. ${ }^{3}$ As with personal wealth, there was little variation across the groups. Regardless of their political inclinations, respondents displayed a strong preference for living in a society that is more equal than is currently the case in Australia.

Preferences for different societies 
To examine relative preferences for living in the different hypothetical countries, we took each respondents' rating for each distribution (ranging from 0 to 100), and calculated their preferred distribution across each possible pairing of countries. For instance, a respondent who gave Country A a score of 80 and Country B a score of 50 was coded as having a preference for Country A. From this we determined the percentage of respondents who preferred one country over another. Figure 3a and 3b display these relative preferences, suggesting that Australians strongly favor societies that are more equal. Compared to the society in which, unbeknownst to them, they actually lived, almost three-quarters of Australians preferred a society with only a small degree of inequality, and two-thirds preferred a society that was fully equal. The society in which respondents actually lived was more appealing than an even more unequal society (the US), with two-thirds of respondents preferring Australia's distribution over the US distribution (Figure 3b).

Perceptions of and attitudes towards policy changes

We next examined Australians' estimates of - and attitudes towards - the minimum wage. Just as respondents overestimated the percent of wealth owned by the poorest quintile, they also overestimated the minimum wage, with their estimated mean of AUD\$16.80/hour nearly AUD $\$ 2.00$ more than the actual national adult minimum wage at the time of survey (AUD\$15.00/hour). We also segmented the sample according to party identification, gender and age. As Table 2 shows, this overestimation of the minimum wage emerged across all demographic variables. However, the extent of overestimation varied depending on certain demographics. For instance, females gave more accurate estimates of the minimum wage than did males, $t(996)=2.07, p=.039$. A linear regression analysis revealed that respondents' personal income predicted their estimates of the minimum wage, $B=.11, S E=.05, t(985)=3.44$, $p=.001$, with lower income respondents predicting significantly lower levels than higher income 
respondents. ${ }^{4}$ Personal wealth also marginally predicted minimum wage estimates, $B=.06$, $S E=.04, t(994)=1.88, p=.061$.

Despite their generally inflated estimates of the minimum wage, our results suggest that Australians were strongly supportive of further increases (mean=5.73 on 7-point scale). Table 2 presents ratings across the demographic variables, showing high levels of support for increasing the minimum wage across all key demographics. However, again there were some notable differences. Support was significantly stronger among females than males, $t(996)=-5.31$, $p<.001$. Further, support significantly varied as a function of political affiliation, $F(2,992)=$ 14.41, $p<.001$, with simple contrasts revealing that those who identified with the ALP, Greens, or Democrats, showed stronger support for increasing the minimum wage than unaffiliated respondents, $t(992)=2.37, p=.018$, who in turn were more supportive than Liberal and National Party respondents, $t(992)=3.46, p=.001$. Finally, linear regression demonstrated that as respondents' wealth increased, their support for increasing the minimum wage declined, $B=-.05$, $S E=.01, t(994)=4.26, p<.001$.

We next examined support for government intervention in addressing wealth inequality. While support was not as strong as for increasing the minimum wage, overall there was some support across the sample for government intervention in policies that increase wealth equality (mean=4.98 on a 7-point scale). However, this significantly differed according to political affiliation, $F(2,992)=47.66, p<.001$ (see Table 2). As simple contrasts reveal, respondents who identified with the ALP, Democrats or Greens showed significantly greater support than unaffiliated respondents, $t(992)=5.22, p<.001$, who in turn showed significantly more support than respondents affiliated with the Liberal or National Party, $t(992)=5.47, \mathrm{p}<.001$. However, even the lowest scores were above the midpoint, indicating that conservative, liberal, and independent voters still endorse government intervention on the issue. 
Thus despite some differences, respondents expressed considerable support overall for raising the minimum wage and other government intervention, suggesting that regardless of political ideology, gender, or personal wealth, Australians would like a society in which the poor are better off.

\section{Relationships between estimated and ideal inequality and policy preferences}

We next examined how people's estimates of the wealth distribution in Australia - and their ideal distributions - were related to their attitudes towards increasing the minimum wage and government intervention. Attitudes towards a minimum wage increase were not related to how much wealth respondents actually perceived the bottom quintile to own, $r(995)=-.04, p=.20$. Attitudes were only very weakly related to how much wealth they believed the bottom quintile should own, $r(995)=.12, p<.001$. Further, attitudes towards increasing the minimum wage were only weakly correlated with the difference between respondents' actual and ideal distribution for this quintile, $r(995)=.11, p=.001$. In other words, a belief that the bottom quintile has much less wealth than they should ideally have only weakly predicted more positive attitudes towards increasing the minimum wage. Overall, these results suggest that people’s views about how much wealth the poorest quintile should own are not closely tied to their attitudes towards raising the minimum wage.

We also examined how respondents' estimates and ideal wealth distributions related to their agreement/disagreement with the statement, “Government should adopt policies that promote wealth equality in Australia.” Respondents' support for this statement was not correlated with how much wealth they estimated the poorest quintile to have, $r(995)=-.05, p=.08$, and was weakly associated with how much wealth they believed that the poorest quintile should have, $r(995)=.21, p<.001$. As with the minimum wage, given that these correlations were consistently either weak or non-significant, Australians’ beliefs about wealth distribution 
evidently are not closely aligned with their attitudes towards wealth-equalizing government policies.

\section{Discussion}

Using a nationally representative Australian sample, the present study replicates the primary findings of Norton and Ariely (2011), thereby demonstrating that those earlier findings are not driven by ideological or economic conditions unique to the US. As in the US study, Australians perceived far less of a gap between the rich and the poor than actually exists. This tendency emerged even when people made estimates for the wealth quintile to which they themselves belonged, suggesting that the rich systematically underestimate their share of the wealth, and the poor systematically overestimate theirs.

As in the US, despite underestimating the extent of wealth inequality, Australians favor a society that is even more equal than their optimistic misperception, preferring a society in which wealth inequality does not exist (i.e., all quintiles own the same) to their own society by a margin of two to one. This preference for greater equality was also present in Norton and Ariely’s (2011) US sample, although not to the same extent. Notably, in line with Norton and Ariely (2011), ideal and actual estimates of wealth distribution were strikingly similar regardless of personal wealth and political affiliation, suggesting that all Australians tend to favor a society that is more equal than it is at present. One potential alternative explanation for our results is that they may be driven in part by desires to appear "politically correct” by stating one's belief in equality (e.g., Norton, Sommers, Apfelbaum, Pura, \& Ariely, 2006). However, we note that respondents in previous research often report less-than-politically-correct beliefs; for example, whereas liberals view poverty as the result of injustice, conservatives blame poverty on selfindulgence and moral failings (e.g., Sniderman, Hagen, Tetlock, \& Brady, 1986), and White Americans now report that Whites are greater victims of racial discrimination than Blacks 
(Norton \& Sommers, 2011). Still, future research is needed to explore the extent to which concerns about political correctness may influence our results.

Do these beliefs about wealth inequality translate to support for redistributionist policy mechanisms, such as the minimum wage? Our results suggest the link is weak. Although Australians generally favored an increase in the current minimum wage, support was only weakly correlated with beliefs that the poorest quintile should ideally have more wealth than they currently do. Similarly, the correlation between the belief that the poorest quintile should have more of the wealth and support for policies that increase wealth equality were also fairly weak. Overall, this suggests that preferences for a more equal society do not clearly map onto support for policy actions that will effect such change, in line with other research suggesting a disconnect between citizens' general political beliefs and their attitudes towards specific policies (e.g., Bartels, 2005).

On the one hand, this weak relationship may be driven by the fact that people systematically overestimate the actual wealth of the poorest in society. This misperception may work to decouple people's beliefs about ideal wealth distributions from their beliefs about policy mechanisms — effectively making people feel like the problem is less urgent than they may otherwise feel. Accordingly, future research might address whether informing people about actual wealth disparities strengthens the link between their personal ideal society and their support for policy mechanisms that address wealth inequality; previous research does suggest that such perceptions are malleable (e.g., Chow \& Galak, 2012; Savani \& Rattan, 2012). On the other hand, the weak relationship may be driven by the fact that people do not perceive the minimum wage as an effective tool for addressing wealth inequality. If this is the case, enhancing accuracy of wealth distribution estimates will have little impact on support for such policies that reduce inequality. In this scenario, alternative policy mechanisms, such as 
strengthening progressive taxation, may provide more fruitful avenues for closing the gap between ideal and actual wealth distributions.

\section{Conclusion}

Differences in the distribution of outcomes among citizens underlie many of the most pressing political issues: Should all citizens receive universal health care? Should affirmative action policies be discontinued or preserved? Should everyone pay the same income tax, or should some pay more than others? Not surprisingly, such questions prompt heated debates within individual countries, with members of different political parties often holding diametrically opposed views. The current results demonstrating Australians' consensus desire for a more equal Australia - taken together with Norton and Ariely’s (2011) results suggesting a similar desire among Americans for a more equal America - suggest that underlying such fierce partisan debates is a relatively consistent cross-cultural belief that wealth should be more equally distributed than is currently the case. 


\section{References}

ABS. (2006). Household wealth and wealth distribution, Australia, 2003-2004, cat. no. 6554.0, Canberra.

ABS. (2007). Household wealth and wealth distribution, Australia, 2005-2006, cat. no. 6554.0, Canberra.

ABS. (2009). Household income and income distribution, Australia, 2007-2008, cat. no. 6523.0, Canberra.

ABS. (2011). Household wealth and wealth distribution, Australia, 2009-2010, cat. no. 6554.0, Canberra.

Bartels, L.M. (2005). Homer gets a tax cut: Inequality and public policy in the American mind. Perspectives on Politics, 3, 15-31.

Chow, R. M. \& Galak, J. (2012). The effect of inequality frames on redistributive income policy support. Psychological Science, 23, 1467-1469.

Greenfield, B. (2012). The world's richest countries. Retrieved from http://www.forbes.com/sites/bethgreenfield/2012/02/22/the-worlds-richest-countries/

Kumhof, M., \& Ranciere, R. (2010). Inequality, leverage and crises. IMF Working Paper, 10/268.

Napier, J.L., \& Jost, J.T. (2008). Why are the conservatives happier than the liberals? Psychological Science, 19, 565-572.

Norton, M., \& Ariely, D. (2011). Building a better America - One wealth quintile at a time. Perspectives in Psychological Science, 6, 9-12. 
Norton, M.I. \& Sommers, S.R. (2011). Whites see racism as a zero-sum game that they are now losing. Perspectives on Psychological Science, 6, 215-218.

Norton, M.I., Sommers, S.R., Apfelbaum, E.P., Pura, N., \& Ariely, D. (2006). Color blindness and interracial interaction: Playing the Political Correctness Game. Psychological Science, 17, 949-953.

OECD. (2011). Divided We Stand: Why Inequality Keeps Rising, OECD Publishing. http://dx.doi.org/10.1787/9789264119536-en

Pickett, K.E., \& Wilkinson, R.G. (2010). Inequality: An underacknowledged source of mental illness and distress. British Journal of Psychiatry, 197, 426-8.

Rawls, J. (1971). A theory of justice. Cambridge, MA: Harvard University Press.

Savani, K.S. \& Rattan, A. (2012). A choice mind-set increases the acceptance and maintenance of wealth inequality. Psychological Science, 7, 796-804.

Sniderman, P. M., Hagen, M. G., Tetlock, P. E., \& Brady, H. E. (1986). Reasoning chains: Causal models of policy reasoning in mass publics. British Journal of Political Science, 16, 405-430.

Wilkinson, R.G., \& Pickett, K.E. (2009). The spirit level: Why greater equality makes societies stronger. New York: Bloomsbury. 


\section{Footnotes}

${ }^{1}$ Note that the distribution provided to respondents in the study differs slightly to that shown in the Results (Figure 1). This is because at the time of data collection, we did not have access to the most recent figures.

${ }^{2}$ To ensure that respondents' estimates and ideals were always perfectly descending, with the top quintile always owning the most wealth and the poorest quintile owning the least, we ordered the values provided by respondents from highest to lowest.

${ }^{3}$ In Group 3 we note that the overwhelming majority (91\%) listed their political affiliation as “none”. As such, this group likely reflects centrist or independent voters.

${ }^{4}$ We report standardized regression coefficients in all analyses. 
Table 1. Demographic profile of respondents $(N=998)$.

\begin{tabular}{ll}
\hline & ALP/Greens/Democrats $(n=327)$ \\
Party Identification* & $\begin{array}{l}\text { Liberal/National }(n=246) \\
\text { Other/unaffiliated }(n=422)\end{array}$ \\
\hline Geographic Location & Metro $(n=701)$ \\
& Regional $(n=297)$ \\
\hline Gender & Female $(n=495)$ \\
& Male $(n=503)$ \\
& $18-24(n=176)$ \\
& $25-34(n=214)$ \\
& $35-44(n=205)$ \\
$45-54(n=213)$ & $55+(n=190)$
\end{tabular}

*Three respondents did not report party identification; as such, for this variable, $N=995$. 
Table 2. Estimates of minimum wage and support for raising the minimum wage.

\begin{tabular}{|c|c|c|c|c|}
\hline $\begin{array}{l}\text { Demographic } \\
\text { category }\end{array}$ & Level within category & $\begin{array}{l}\text { Mean estimate } \\
\text { of current } \\
\text { minimum } \\
\text { wage (AUD\$) }\end{array}$ & $\begin{array}{l}\text { Mean level of } \\
\text { support for } \\
\text { raising the } \\
\text { minimum wage* }\end{array}$ & $\begin{array}{l}\text { Mean level } \\
\text { of support } \\
\text { for } \\
\text { government } \\
\text { intervention } \\
\text { in } \\
\text { addressing } \\
\text { wealth } \\
\text { inequality* }\end{array}$ \\
\hline \multirow{3}{*}{$\begin{array}{l}\text { Party } \\
\text { identification }\end{array}$} & $\begin{array}{l}\text { ALP/Greens/Democrats } \\
(n=327)\end{array}$ & $17.01_{a}$ & $5.95 \mathrm{a}$ & $5.47 \mathrm{a}$ \\
\hline & $\begin{array}{l}\text { Liberal/National } \\
(n=246)\end{array}$ & $17.22_{\mathrm{a}}$ & $5.40_{\mathrm{c}}$ & $4.36_{c}$ \\
\hline & $\begin{array}{l}\text { Other/unaffiliated } \\
(n=422)\end{array}$ & $16.37 \mathrm{a}$ & $5.74_{b}$ & $4.95_{b}$ \\
\hline \multirow{2}{*}{ Gender } & Female $(n=495)$ & $16.47 \mathrm{a}$ & $5.93_{a}$ & $4.89_{\mathrm{a}}$ \\
\hline & Male $(n=503)$ & $17.13_{b}$ & $5.52_{b}$ & $5.06_{a}$ \\
\hline \multirow{5}{*}{ Age } & $18-24(n=176)$ & $17.44_{\mathrm{a}}$ & $5.61_{\mathrm{a}}$ & $4.83_{\mathrm{a}}$ \\
\hline & $25-34(n=214)$ & $16.55_{a}$ & $5.65_{\mathrm{a}}$ & $4.88_{a}$ \\
\hline & $35-44(n=205)$ & $16.67 \mathrm{a}$ & $5.83_{\mathrm{a}}$ & $5.09_{a}$ \\
\hline & $45-54(n=213)$ & $16.45 \mathrm{a}$ & $5.87 \mathrm{a}$ & $5.10_{\mathrm{a}}$ \\
\hline & $55+(n=190)$ & $17.01_{\mathrm{a}}$ & $5.64_{a}$ & $4.96 \mathrm{a}$ \\
\hline Overall & & 16.80 & 5.73 & 4.98 \\
\hline
\end{tabular}

Note: Within each demographic category, for each variable, mean estimates with a different subscript significantly differ from one another, $p<.05$.

* Measured on a 7-point scale ranging from 1 (strongly oppose) to 7 (strongly approve) 
Figure 1. Actual, estimated and ideal wealth distributions by quintile in Australia and the US; US data from Norton and Ariely (2011).

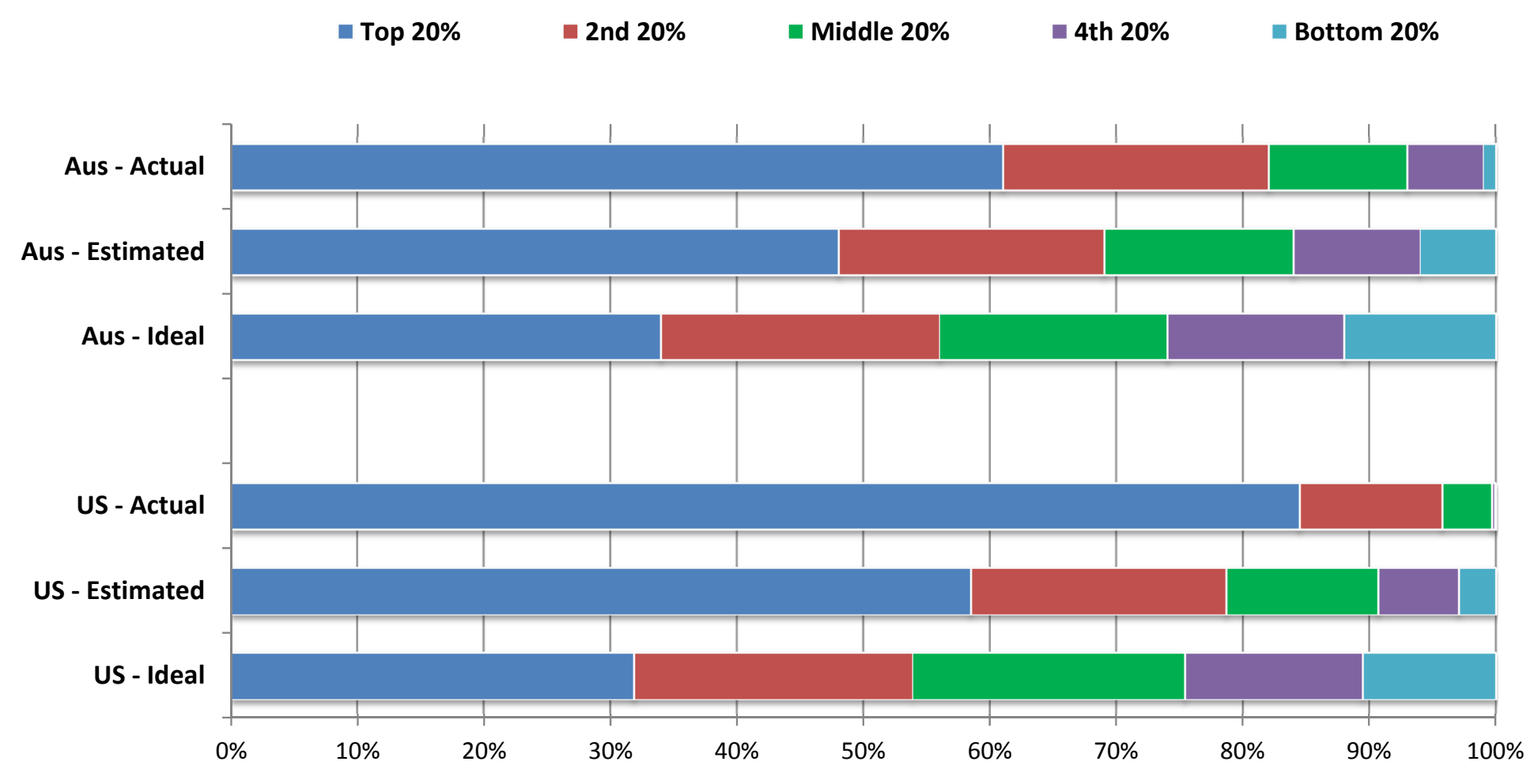

Percent Wealth Owned

Note: Because of their small percentage share of total wealth, both the " 4 th $20 \%$ " value $(0.2 \%)$ and the "Bottom $20 \%$ " value (0.1\%) are not visible in the "Actual” US distribution. 
Figure 2. The actual Australian wealth distribution plotted against the estimated and ideal distributions of respondents of different income levels and political affiliations.

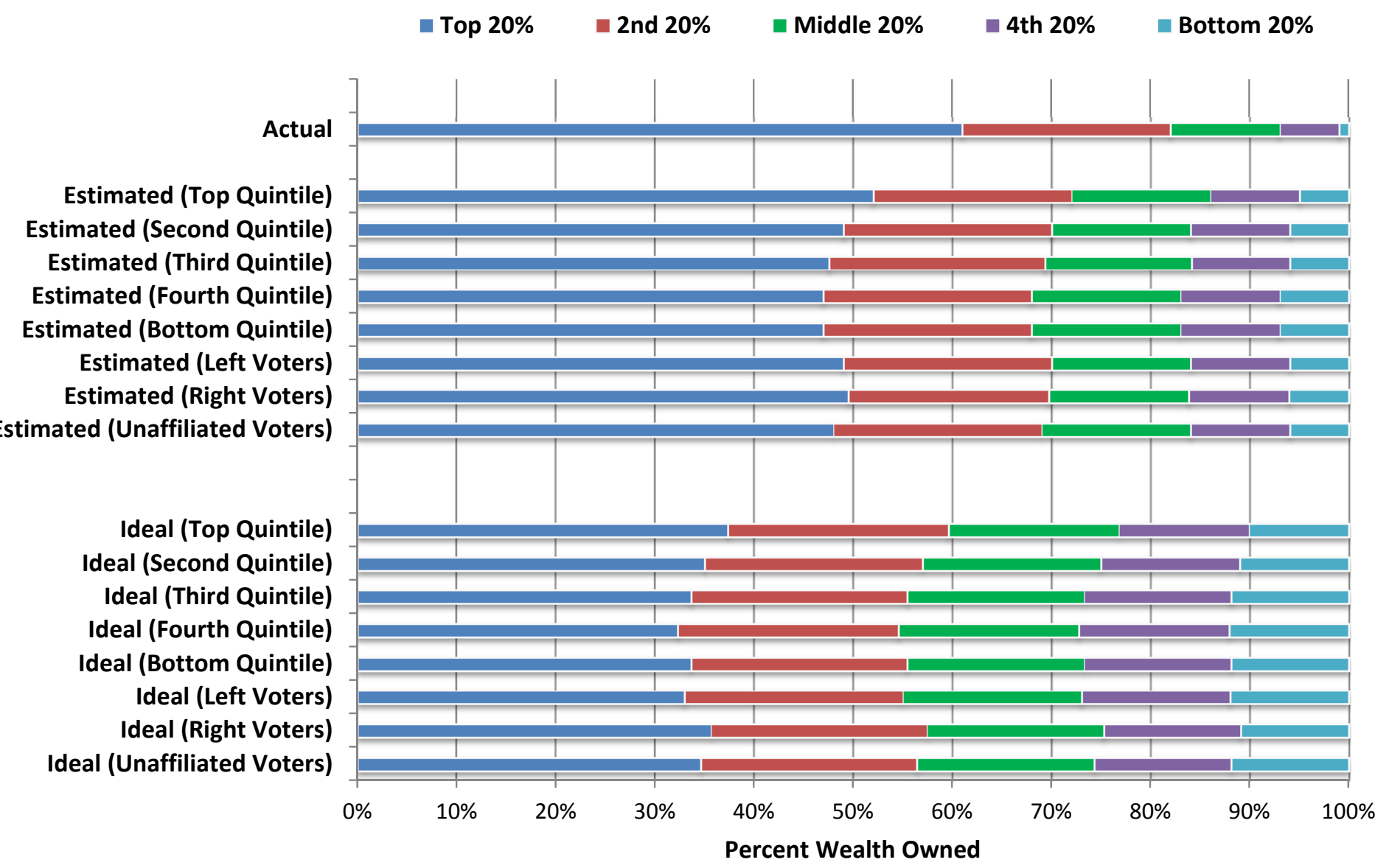


Figure 2a. Preferences for actual Australian wealth distribution vs. US respondents' ideal society vs. fully equal society. Pie charts depict the percentage of wealth possessed by each quintile; for instance, in Australia, the top wealth quintile owns $61 \%$ of the total wealth, the second highest $21 \%$, and so on.

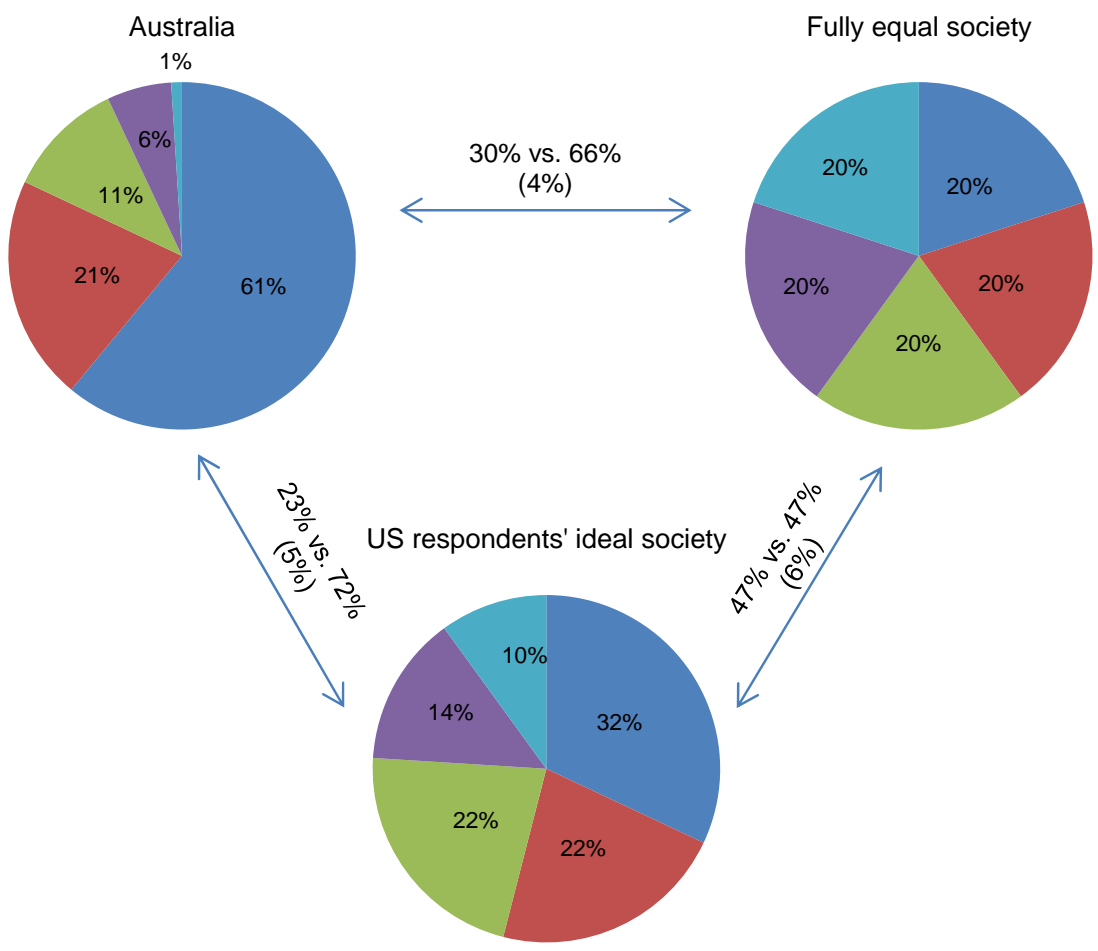

Figure 2b. Preferences for actual Australian vs. actual US wealth distributions. Pie charts depict the percentage of wealth possessed by each quintile; for instance, in Australia, the top wealth quintile owns $61 \%$ of the total wealth, the second highest $21 \%$, and so on
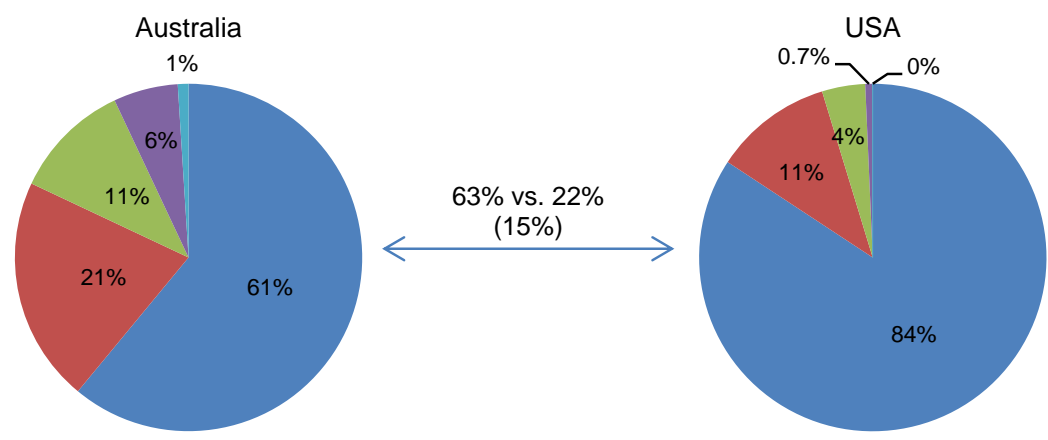